\title{
ARTES MARCIAIS E LUTAS: \\ UMA ANÁLISE DA \\ PRODUÇÃO DE SABERES NO \\ CAMPO DISCURSIVO DA \\ EDUCAÇÃO FÍSICA BRASILEIRA'
}

\author{
MS. ARISSON VINÍCIUS LANDGRAF GONÇALVES \\ Programa de Pós-Graduação em Educação em Ciências: química \\ da vida e saúde, Universidade Federal do Rio Grande \\ (Rio Grande - Rio Grande do Sul - Brasil) \\ E-mail: arissonvinicius@yahoo.com.br
}

\author{
DRA. MÉRI ROSANE SANTOS DA SILVA \\ Instituto de Educação, Universidade Federal do Rio Grande \\ do Sul (Rio Grande - Rio Grande do Sul - Brasil) \\ E-mail: meri.rosane@hotmail.com
}

\begin{abstract}
RESUMO
A discussão acerca das Artes Marciais e das Lutas tem aparecido com mais frequência no cenário acadêmico da Educação Física nacional. Diante disso, este estudo tem por objetivo identificar e problematizar como estas práticas são produzidas como um saber pertinente a ser abordado por essa área de conhecimento. A partir de algumas noções de análise discursiva, inspiradas no referencial teórico de Michel Foucault, pode-se dizer, através da seleção de artigos de cinco periódicos nacionais, que as concepções de Artes Marciais e de Lutas aparecem como duas formações discursivas em disputa produtiva. Dessa forma, elas tecem um campo de batalha discursiva que constitui modos de pensar, praticar e falar dessas práticas, a partir das diferentes bases epistemológicas que as sustentam.
\end{abstract}

PALAVRAS-CHAVE: Artes marciais; lutas; campo discursivo; discurso científico.

I. O presente trabalho contou com o financiamento da CAPES (modalidade bolsa de mestrado). 
Os diferentes significados atribuídos às Artes Marciais e às Lutas têm possibilitado sua circulação e apropriação por várias esferas da sociedade. Atualmente, podemos considerá-las atividade de lazer, exercício que visa o aumento da aptidão física, defesa pessoal, prática esportiva, além de serem constantemente associadas a um estilo de vida e orientadas por determinados valores culturais. Essas práticas, ${ }^{2}$ como objeto de significação, ganham cada vez mais espaço em academias de ginástica, clubes esportivos, escolas, entre outros ambientes, tornando-se suscetíveis a um "complexo e indeterminado processo de transformação" (SILVA, 2003, p. 20), o que possibilita a elas que se manifestem imbricadas em diferentes contextos sociais.

No que diz respeito ao conhecimento produzido sobre elas no universo acadêmico, especificamente através da Educação Física, a situação não é diferente. São elas entendidas tanto como uma atividade milenar, atrelada a determinadas orientações filosóficas e religiosas, quanto uma atividade física e esportiva, apropriada por práticas escolares e não-escolares. Na tentativa de delimitar os significados dessas práticas corporais, estudos como o de Correia e Franchini (20 I0) indicam a possibilidade de nomeá-las de três maneiras diferentes: ${ }^{3}$ ( I ) Artes Marciais, (2) Luta e (3) Modalidades Esportivas de Combate. No mesmo sentido, Gomes et al. (20 I0) também sugerem definições que, por sua vez, delimitam as Artes Marciais ou Lutas a uma concepção esportiva. Assim, elas aparecem assumindo múltiplos significados. No que concerne à atribuição e produção de sentidos, é possível afirmar que este tema aparece de forma variada de acordo com as bases epistemológicas que se propõem discuti-lo. Logo, encontramos maneiras diferentes de nomear uma mesma prática, bem como práticas diferentes reconhecidas pelo mesmo nome. Com isso, falar sobre elas nos afasta de definições acabadas. Artes Marciais e Lutas, por exemplo, são termos muitas vezes utilizados sem que se suspeite ou problematize o que, de fato, nomeiam.

Diante disso, proponho neste artigo indicar um modo de pensar sobre essas práticas que escape das formas pelas quais estão sendo predominantemente

2. A utilização do termo práticas será utilizada como sinônimo de Artes Marciais e de Lutas. Porém, ele não se restringe apenas a fazer referência aos movimentos corporais que as caracterizam. Mais que isso, ele remete ao entendimento de que Artes Marciais e Lutas são práticas produzidas e produtoras de sentido no funcionamento da linguagem. Nesse sentido, a própria produção acadêmica sobre o assunto se constitui como uma prática que ativa a produção dessas formações discursivas.

3. As três definições propostas por Correia e Franchini (2010) parecem bem demarcadas, porém, considerarei apenas os dois primeiros termos, ( 1 ) artes marciais e (2) lutas, para discutir a tensão que eles exercem num espaço de significação dessas práticas. Isso não quer dizer que o terceiro termo apontado, (3) modalidades esportivas de combate, seja excluído, apenas considero que o significado atribuído a este, já esteja imbricado no segundo termo utilizado pelos autores. 
pensadas e produzidas pelos discursos reiterados por textos acadêmicos nacionais atualmente. Em outras palavras, lanço um olhar de suspeita ao assunto a fim de problematizar a multiplicidade de sentidos atribuídos. Para isso, inspirando-me em Foucault (2008, p. I 58), realizo um primeiro movimento que implica o esforço de um "tríplice deslocamento" em relação ao objeto de análise. Três cuidados que aqui assumo, como: ( I ) descentrar-me das tentativas de definições prontas acerca do tema; (2) deslocar-me de bases epistemológicas que fixam essa discussão, sob determinados aspectos, e (3) recusar-me a adotar o conhecimento produzido sobre essa temática de forma naturalizada, como algo instituído e aceito, acima de qualquer suspeita.

Com isso, a questão norteadora deste artigo toma forma e o que se torna interessante aqui é perceber de que maneira esse tema é entendido, de modo a se constituir em um objeto de saber (FOUCAULT, 20 I 0). Objeto que a Educação Física dedica-se a relacionar, classificar e nomear, tecendo uma rede de conhecimentos sobre ele à luz de um discurso científico. Ou melhor, como estas práticas aparecem no universo acadêmico e científico a partir do que se fala sobre elas? Como o movimento de produção do conhecimento constitui um saber pertinente aos domínios da Educação Física?

Indo mais adiante, diria que se deslocar dos pensamentos instituídos sobre as Artes Marciais e as Lutas indica outro movimento que me leva a reconhecer na linguagem, ${ }^{4}$ a possibilidade de entendê-las como produtos de conceitos, juízos e verdades fabricados tanto por seus adeptos ou acadêmicos quanto por aqueles que não foram interpelados por elas. Através da linguagem, enquanto "objeto de nosso saber e matéria-prima de nossas ações" (LAROSSA, 200I, p. 70), nos expressamos, nos comunicamos, damos sentido às coisas. É dessa forma que atribuímos e assumimos significados que nos permitem um entendimento plural das Artes Marciais e das Lutas. Nessa perspectiva, tomando a linguagem não apenas como um conjunto de signos, palavras ou frases, mas assumindo-a em sua função enunciativa (FOUCAULT, 20I0), foram analisados 26 artigos que discutem o tema a partir de diferentes perspectivas de pensamentos que constituem a Educação Física brasileira.

O material empírico é proveniente de cinco periódicos nacionais que tratam de temas pertinentes a uma abordagem ligada às Ciências Humanas como: Motrivivência, Motriz, Movimento, Pensar a Prática e Revista Brasileira de Ciências do Esporte (RBCE). A seleção dos artigos foi realizada a partir da temática abordada.

4. Sem restringi-la a sua forma verbal, mas considerando-a em sua multiplicidade, Larrosa (200 I ), a partir das hipóteses nietzscheanas, aponta a linguagem como um dos produtos do instinto de conservação da vida humana, ou seja, uma forma de expressar e constituir os modos particulares de vida em sociedade. Através dela, se consolida o que mais adiante deve ser entendido como verdade e contrastado do que é mentira. 
Assim, a busca se deu a partir dos títulos e resumos de todas as edições dos periódicos delimitados, a fim de encontrar textos que se dedicaram a discutir as Artes Marciais e as Lutas como tema central.

Tendo em vista as possibilidades de discussões, dedico-me a problematizar as concepções produzidas pelo universo científico acerca dessas práticas, restringindo-me àquelas reconhecidas por seus vínculos culturais com o extremo oriente. ${ }^{5}$ Para isso, opero com a noção de análise discursiva, assumindo como movimento de pesquisa a descrição de dispersões enunciativas na busca de diversas possibilidades de se ativar um tema e produzir diferentes maneiras de se pensar sobre ele (FOUCAULT, 20 I 0). Assim, a análise realizada exigiu um trato do corpus empírico como um conjunto de elementos enunciativos. Os textos selecionados são peças, formações discursivas que constituem e acionam um discurso acerca das Artes Marciais e das Lutas, e sua relação com a Educação Física brasileira. São enunciados ${ }^{6}$ que ativam manifestações de um saber, produzindo determinadas maneiras de pensar e conceituar assuntos pertinentes à determinada área de conhecimento (VEIGA-NETO, 2007).

\section{ARTES MARCIAIS OU LUTAS? TECENDO UM CAMPO DE BATALHA}

A partir dos artigos delimitados para a análise, foi possível ensaiar alguns pensamentos sobre as práticas discursivas ${ }^{7}$ que sustentam e significam as Artes Marciais ou Lutas como objeto de pesquisa. Nas publicações, elas aparecem tanto como assunto central de discussão quanto como cenário para abordar outros assuntos, dentre os quais gênero, educação física escolar, atividade física e treinamento desportivo. No que diz respeito às discussões estabelecidas nos textos, os argumentos sustentados por seus autores indicam a existência de um campo de disputa tensionado entre dois conjuntos de formações discursivas, que constituem a noção de Artes Marciais distinguindo-a da concepção de Lutas. Isto é, um campo discursivo, "um conjunto de formações discursivas que se encontram em relação de concorrência, em sentido

5. Para evitar possíveis equívocos, considero para este trabalho apenas as práticas de Artes Marciais e de Lutas provenientes de uma cultura extremo oriental. Reconheço a existência de práticas ligadas a outras culturas ocidentais e do oriente médio - e por ter consciência de suas diferenças, assumo apenas as do extremo oriente como objeto de análise. Desse modo, restrinjo esta análise às discussões acerca das práticas reconhecidas como: Karatê, Taekwondo, Judô e Kendo, por se tratar de modalidades presentes nos artigos selecionados.

6. É importante ressaltar que a noção de enunciado, de acordo com Foucault (2010), não se restringe a frases ou parágrafos. Por mais que o material empírico analisado neste estudo tenha sido composto por artigos acadêmicos, eles assim foram considerados pela função enunciativa que exercem, ou seja, "uma função que cruza um domínio de estruturas e de unidades possíveis e que faz com que apareçam, com conteúdos concretos, no tempo e no espaço" (p.98).

7. De acordo com Foucault (20 I0, p. I33), práticas discursivas trata-se de um conjunto de regras anônimas, históricas, sempre determinadas no tempo e no espaço, que definiram em uma dada época e para uma determinada área social, econômica, geográfica ou linguística, as condições de exercício da função enunciativa". 
amplo, e se delimitam, pois, por uma posição enunciativa em uma dada região" (MAINGUENEAU, 1997, p. I16).

Com base nos 26 artigos analisados, são marcantes as tentativas de definir uma classificação que dê conta de fixar determinado modo de nomear e dar sentido a essas práticas corporais. Alguns as assumem enquanto Artes Marciais, outros tratam como Lutas, sem mencionar outras formas esporádicas de classificá-las como Modalidades Esportivas de Combate ou, até mesmo, Jogos de Lutas. Mas que diferença isso implica? Do ponto de vista acadêmico parece que a utilização de diferentes termos para falar de atividades tão parecidas está associada à ênfase que se deseja dar à perspectiva pela qual elas são discutidas. Assim, analisá-las por um viés pedagógico, por exemplo, implicaria classificá-las e nomeá-las diferentemente de quando são abordadas em uma perspectiva esportiva de alto-rendimento.

Contudo, é importante destacar que esta disputa nem sempre se configurou dessa forma, movimentando diferentes concepções nos domínios da Educação Física. Podemos dizer que essas práticas passam a constituir um saber pertinente ao universo acadêmico, principalmente, a partir do momento que são entendidas como práticas esportivas, caracterizadas por passarem por um possível processo de esportivização, que converte ou transforma essas práticas em esporte, ${ }^{8}$ através da apropriação dos códigos que orientam esse fenômeno (GONZÁLEZ, 2005). Especificamente, é através do estabelecimento da proposta de regulamentação da profissão de Educação Física ${ }^{9}$ que essas práticas passam a compor um campo de disputa por sua legitimidade. Como tema de pesquisa, elas começam a constituir um assunto passível de ser conhecido, relacionado e nomeado de formas e em lugares determinados. As diversas maneiras de entendê-las e executá-las passam a constituir um conhecimento pertinente a diferentes perspectivas de ciência acionadas pelo funcionamento da Educação Física.

Através da análise, a operação de descrever a forma como essas práticas são tratadas, no que concerne ao conhecimento que é produzido sobre elas, implicou na diferenciação entre o que se apropria por Artes Marciais e o que é considerado Lutas. Termos que, aparentemente, significam a mesma prática exercem tensionamentos

8. Importante ressaltar que o significado esportivo que me refiro diz respeito à definição de esporte enquanto prática motora/corporal que González e Fensterseifer (2005) caracterizam por seus aspectos como: comparação de desempenho e igualdade entre adversários, asseguradas por um quadro de regras normalmente estabelecido por instituições responsáveis por promover e homogeneizar determinada prática.

9. De acordo com Gonçalves Junior e Drigo (200 I), a partir da legislação que regulamenta a profissão de educação física inicia-se um embate pela disputa de quem possui competência para discutir e promover a prática dessas manifestações corporais. Formalmente, este campo de disputa é configurado pelo tensionamento entre o Conselho Federal de Educação Física e as Confederações Brasileiras de Lutas e Artes Marciais. Neste artigo não me dedicarei a esta discussão, apenas reconheço como sendo um acontecimento importante que possibilita a essas práticas serem reconhecidas de maneiras diversas na contemporaneidade. 
contrários nesse campo de batalha. A maneira pela qual são tratadas indica a formação de dois espaços discursivos. Dois pontos concorrentes: o das Artes Marciais e o das Lutas. Para Maingueneau ( 1997, p. I I 7), o espaço discursivo "delimita um subconjunto do campo discursivo, ligando pelo menos duas formações discursivas que, supõe-se, mantêm relações privilegiadas, cruciais para a compreensão dos discursos considerados". De acordo com o autor, a determinação desses subconjuntos se dá pela impossibilidade de apreender um campo discursivo em sua totalidade. No caso das Artes Marciais e das Lutas, os subconjuntos se caracterizam por concepções opostas aplicados a uma mesma prática, e/ou semelhantes, mas que mesmo em disputa, são produtivas para constituição do tema.

A partir dos textos analisados, nomear certas práticas por Artes Marciais enfatiza determinada noção geográfica, moral e cultural do que entendemos por Oriente. Uma ideia que se aproxima do que Foucault (2009, p. 17) reconhece por origem e se caracteriza pela busca de uma "essência exata da coisa, sua mais pura possibilidade, sua identidade cuidadosamente recolhida em si mesma, sua forma imóvel e anterior a tudo o que é externo, acidental, sucessivo". Os enunciados que constituem essa concepção podem ser aproximados de uma noção orientalista, como considera Edward Said (2007). ${ }^{10}$ Assim, os artigos interpelados por essa noção, apontam para a valorização do "Oriental" como sinônimo do que é exótico, misterioso, profundo e seminal.

De acordo com Said (2007, p. 274) "a palavra Oriente possui uma grande ressonância cultural no Ocidente". E é exatamente neste "Oriente" cultural que o conjunto de formações discursivas ativa a noção de Artes Marciais, reforçando a ideia de que são práticas vinculadas a determinados valores morais que produzem uma conduta específica, um estilo de vida que "envolve o sujeito em outras dimensões de sua existência dentro e fora da área de luta" (RODRIGUES, 2009, p. 649). Assim, elas se caracterizam por valorizar determinadas verdades, esforçando-se para recolher nelas mesmas uma origem exata, anterior a tudo que é externo.

Dentro dessa concepção, podemos recortar alguns exemplos que nos ajudam a entender como se constitui o que podemos reconhecer por Artes Marciais. Rios (2005), na tentativa de resgatar e sistematizar a história do taekwondo, considera que essa modalidade, ao passar por um processo de esportivização iniciado em 1960, perdeu alguns elementos que a caracterizava como Arte Marcial, salientando que o:

10. Edward Said (2007) chama por Orientalismo o interesse - principalmente econômico - europeu e depois americano em estudar o Leste: o Oriente. Assim, o autor considera que a cultura ao atuar dinamicamente com a lógica política, econômica e militar fez do Oriente um lugar variado e complicado que fomentou o Orientalismo enquanto campo de estudo. 
praticante de arte marcial desenvolvia técnicas que, se numa situação real de luta precisasse usá-las, derrubaria o oponente em poucos segundos. Para a apropriação dessas técnicas era necessário longo tempo, tempo que não era mais disponível, já que o novo estilo reservava este [tempo] para o treinamento de técnicas permitidas nas competições (RIOS, 2005, p. 50).

É possível perceber que o olhar lançado pelo autor é orientado por um aspecto saudosista, tendendo a desqualificar outros entendimentos possíveis atribuídos a ela. Não distante disso, Yonezawa (2010, p. 248) tece um elogio "filosófico e ético à prática do combate em relação à noção de luta", ao considerar que elas atravessaram diversas mutações até adquirirem seu formato atual e culminarem em uma "transformação das Artes Marciais no que hoje se chama de técnicas de luta". O autor utiliza a expressão "máquina de guerra", com base na filosofia de Gilles Deleuze e Félix Guattari, para se referir à cultura filosófica e espiritualista das Artes Marciais, enquanto máquina produtora de determinados sentidos, atrelados a um modo de pensar que está além da sua redução em sistemas de luta, tendo como meta apenas o confronto bélico:

Assim, trazemos aqui a noção de combate como distinguível ética, política e filosoficamente desta prática estetizada da luta. Como forma também de combate, esboçamos aqui um conceito de combate que possa trazer nova potência às Artes Marciais, talvez, de modo a avivar um pouco de sua força enquanto máquina de guerra (YONEZAWA, 20 I 0, p. 35).

No mesmo sentido, outros artigos referentes a diversas modalidades como o karatê-Do (LAGE ; GONÇALVES JUNIOR, 2007), o kendo (RODRIGUES, 2009) e o judô (DRIGO, 2009) também são assim caracterizados. Sem ferir as singularidades do modo com que cada texto evoca o tema, percebe-se que há uma noção de preservação que os atravessa. Transmitem a ideia da existência de uma essência (boa) que deveria ser preservada e que se perdeu com a transformação ou associação dessas práticas corporais a outros sentidos até então distintos, como é o caso do esporte.

Considerando alguns trechos dos textos analisados, sem julgar suas consistências teóricas, é possível dizer que esses artigos potencializam a ideia de que essas práticas não podem ser desassociadas dos aspectos que as caracterizam como Artes Marciais. No entanto, essa não é a única forma de significá-las. No outro extremo deste tensionamento, está um espaço discursivo que podemos reconhecer por Lutas, constituído por rupturas com a noção estritamente orientalista, ele permite um entendimento mais amplo dessas práticas. Através dele, elas aparecem não só reconhecidas por seus vínculos culturais com o oriente, mas, também, inseridas em outros contextos sociais. É assim que 20 dos 26 textos analisados as tratam, descentrando a noção essencialista das Artes Marciais a fim de discuti-las como 
modalidades esportivas, atividade física ou conteúdo da educação formal. Se num extremo há uma preservação de uma prática original, no outro, está uma concepção que as possibilita serem interpeladas por outros discursos como o da ciência, da saúde, do lazer e do universo esportivo.

Nesse sentido, essas práticas passam a assumir outras configurações que ainda mantêm uma relação mimética com as tradições orientais (ELIAS; DUNNING, 1992)," ' mas que as permitem serem entendidas e discutidas fora do orientalismo. Essa perspectiva sugere a aceitação de outras formas de concebê-las, praticá-las e inventá-las, sem a preocupação de preservar suas essências. As rupturas que constituem essas práticas corporais em sua diversidade de significações são aceitas e muitas vezes desejadas. Referir-se a essas práticas sob essa ótica implica reconhecer nelas, principalmente, um formato esportivo. Hoje, por exemplo, conseguimos diferenciá-las - Judô, Karatê, Taekwondo, entre outras - a partir da visibilidade esportiva que assumem. Esporte este que não restringe a prática ao formato institucionalizado, mas que a possibilita ser apropriada de diversas maneiras e em lugares diferentes.

Na diferenciação estabelecida por essas duas noções, é notável que os artigos que constituem o discurso das Lutas não se restringem a considerar essas práticas corporais apenas por um viés cultural. Em muitos casos, ao utilizar essa expressão, deixa-se de enfatizar o caráter disciplinador, ritualístico e tradicional da cultura Oriental, para associá-la a aspectos pedagógicos, esportivos e relacionados à qualidade de vida. É a partir desse entendimento que muitos autores assumem discuti-las sob aspectos variados como: educacional; ${ }^{12}$ tema pertinente a ser discutido por currículos (TRUSZ; NUNES, 2007) e pesquisas acadêmicas ${ }^{13}$ (CORREIA; FRANCHINI, 20 I0); gênero (FERRETTI; KNIJNIK, 2007); e rendimento esportivo (SILVA; CARVALHO, 2002; CÉSAR et al, 2002).

Ainda nesta perspectiva, dentro da concepção das Lutas, também é possível identificar alguns artigos que desenvolvem argumentos radicalmente contra as concepções essencialistas. Fett e Fett (2009) contestam os dogmatismos que permeiam a formação do professor e dos lutadores. Os autores reconhecem que essas práticas assumiram um formato esportivo que exige conhecimentos científicos, que estão

II. Utilizo "relação mimética" com base em Elias e Dunning (1992), por entender a mimésis como sendo um dos elementos que, por meio de um processo civilizador ou de constituição da modernidade, possibilita a existência dessa manifestação sociocultural que denominamos desporto e que, de acordo com alguns textos analisados, torna pertinente sua aproximação do que no discorrer deste trabalho podemos entender por Artes Marciais ou Lutas.

12. Enquanto conteúdo da educação física escolar (CORDEIRO JUNIOR, I999; SILVEIRA JÚNIOR; CARDOSO, QIGONG, 2004; NASCIMENTO; ALMEIDA, 2007; NASCIMENTO, 2008; CAZETTO, 2008; LOPES; TAVARES, 2008; GOMES et al., 2010;)

13. Algumas pesquisas demonstram a preocupação em formalizar o conhecimento sobre as Lutas, organizando currículos específicos para que esse conhecimento seja transmitido pela educação formal. 
além das limitações impostas pelas tradições das Artes Marciais. Outros autores corroboram a mesma noção quando reivindicam que a

falta de literatura específica e a visão retrógrada de que Judô se treina apenas no dojo acabou por deixar técnicos e atletas sem referencial teórico e prático de métodos mais específicos e sua forma de aplicação (MORAES, apud AZEVEDO et al., 2004, p. 74).

Como é possível observar, essas pesquisas assumem as práticas corporais de Karatê e de Judô como modalidades esportivas institucionalizadas. E, diferentemente dos artigos anteriores, os aspectos culturais atrelados a essas Lutas são colocados em suspeita quanto à funcionalidade, quando objetiva seu desenvolvimento técnico.

Diante disso, é interessante ressaltar que, por mais que alguns artigos não se preocupem em distinguir o uso dos termos Arte Marcial e Lutas, o "tom" no qual esses termos são utilizados implica em diferenciá-los. Na tentativa de estabelecer possíveis definições entre o que seria uma ou outra, o conhecimento que é produzido acerca do assunto constitui um campo de disputa quanto à significação dessas práticas. O sentido que orienta os argumentos encontrados é sempre perpassado por essas duas concepções (de Arte Marcial ou de Lutas) que configuram um campo de batalha discursivo. Porém, isso não significa, a partir da análise, enquadrar cada texto em um dos extremos dessa disputa, mas sim perceber que são eles, através de seus argumentos, que produzem e condicionam este campo que gera saberes e produz "vontade de verdade" (FOUCAULT, 2009, p. I6), que constituem tanto os sujeitos pertencentes a elas quanto aqueles que não são interpelados por tais práticas.

\section{ALGUMAS CONSIDERAÇÕES}

Encerro este artigo - comparando-o ao ato de ensaiar - sem pretensão de esgotar o assunto. Como diria Larrosa (2003, p. 13) sobre o ensaio: "o ensaísta inicia no meio e termina no meio". Ensaiar não no sentido de treinar para algo, mas de exercitar os movimentos de pensamentos que me são possibilitados a partir das condições do cenário que envolve a temática abordada. Sem apresentar grandes conclusões, o que tentei aqui foi desestabilizar a discussão acerca dessas práticas corporais que aos poucos constituem um campo de saber pertinente à Educação Física. Perceber as Artes Marciais e as Lutas enquanto dois espaços discursivos, produtivos e em disputa está longe de querer fixar verdades sobre elas, mas sim dar visibilidade para a emergência de outras práticas de significações que as constituem em diferentes espaços sociais, como é o caso do próprio espaço acadêmico.

Dentre as duas formações discursivas tensionadoras, podemos destacar o primeiro subconjunto por valorizar seus aspectos preservacionistas, que caracterizam uma noção orientalista e possibilitam reconhecer determinadas práticas por Artes 
Marciais. Já o segundo subconjunto, está atrelado a outros significados que nos permitem reconhecê-las como Lutas e associá-las a práticas de lazer, educacionais, atividades físicas e esportivas. Ao reconhecer a dimensão que a discussão sobre este tema assume nos textos acadêmicos, é possível suspeitar que a diversidade de significações não se restrinja à disputa de legitimidade entre as concepções apresentadas. Além de dar visibilidade às Artes Marciais e às Lutas, os artigos apresentam outras formas de olhá-las e as constituem enquanto um saber passível de ser apropriado por diferentes perspectivas do universo científico.

Dessa forma, considerar as Artes Marciais e as Lutas como formações discursivas em concorrência indica a ativação de um campo de batalha discursivo no qual essas práticas corporais são constituídas. Através do conhecimento produzido sobre elas, essas práticas se constituem enquanto objeto de saber de modo que possam ser medidas, avaliadas, equiparadas de diferentes maneiras e aos poucos produzem verdades que se consolidam e orientam não só o que se pode falar e de onde se falar, como também os modos de agir e de pensar sobre o assunto.

Diante disso, esse artigo não trata de estabelecer classificações nem tentar determinar qual a maneira mais correta de tratar este tema. $O$ objetivo central foi o de lançar um olhar e analisar a produção de conhecimento que atravessa a temática das Artes Marciais e das Lutas, decalcando-a em uma rede de significados, sem desconsiderar suas disputas e tensões, mas, atentando para os efeitos que elas produzem na constituição dessas práticas corporais na contemporaneidade.

\section{Fights and Martial Arts: an Analysis of the Production of Knowledge in Brazilian Physical Education Discursive Field}

ABSTRACT: Discussion about the Martial Arts and Fights has appeared more frequently in the academic scenario of the national Physical Education. Thus, this study aims to identify and discuss how these practices are produced as knowledge pertinent to be addressed by this area of knowledge. From some notions of discursive analysis inspired by Foucault's theoretical formulations, we may say, through the selection of articles from five national journals, the conceptions of Martial Arts and Fights appear as two discursive formations in productive dispute. Consequently, they produce a discursive battleground as way of thinking, practicing and talking about these practices, based on the different epistemological foundations that sustain them. KEYWORDS: Martial arts; fights; field discourse; scientific discourse.

\section{Artes marciales y luchas: un análisis de la producción de conocimiento en el campo discursivo de la educación física brasileño}

RESUMEN: La discusión acerca de las Artes Marciales y de las Luchas han surgido con más frecuencia en el escenario académico de la Educación Física nacional. Delante de eso, 
este estudio tiene por objetivo identificar y problematizar cómo esas prácticas son producidas en cuanto un saber pertinente a ser abordado por esa área del conocimiento. A partir de algunas nociones del análisis discursivo inspirado en el marco teórico de Michel Foucault se puede decir, por medio de la selección de artículos de cinco periódicos nacionales, que las concepciones de Artes Marciales y de Luchas aparecen como dos formaciones discursivas en disputa productiva. De esa manera, ellas tejen un campo de batalla discursiva que constituye modos de pensar, practicar y hablar de esas prácticas, a partir de las distintas bases epistemológicas que las sostienen.

PALABRAS CLAVE: Artes marciales; luchas; campo discursivo; discurso de la ciencia.

\section{REFERÊNCIAS}

AZEVEDO, P. et al. Sistematização da preparação física do judoca Mário Sabino: um estudo de caso do ano de 2003. Revista Brasileira de Ciências do Esporte, Campinas, v. 26, n. I, p. $73-86$, set. 2004 .

CAZETTO, F. Lutas e artes marciais na escola: "das brigas aos jogos com regras", de JeanClaude Olivier. Motrivivência, Florianópolis, ano 20, n. 3 I , p. 25I-255, dez. 2008.

CÉSAR, M. et al. Avaliação da intensidade de esforço da luta de caratê por meio da monitorização da freqüência cardíaca. Revista Brasileira de Ciências do Esporte, Campinas, v. 24, n. I, p. 73-8I, set. 2002.

CORDEIRO JUNIOR, O. Em busca da construção de uma proposta teórico-metodológica para o ensino do judô escolar. Pensar a Prática, Goiânia, v. 3, p. 97- 105, jul./jun. I 999/2000.

CORREIA, W. R; FRANCHINI, E. Produção acadêmica em lutas, artes marciais e esportes de combate. Motriz, Rio Claro, v. 16, n. I, p. I-9, jan./mar. 2010.

DRIGO, A. Lutas e escolas de ofício: analisando o judô brasileiro. Motriz, Rio Claro, v. I 5, n. 2, p. 396-406, abr./jun. 2009.

ELIAS. N; DUNNING, E. A busca da excitação. Lisboa: Difel, 1992.

FERRETTI, M.; KNIJNIK, J. Mulheres podem praticar lutas? um estudo sobre as representações sociais de lutadoras universitárias. Movimento, Porto Alegre, v. I3, n. I , p. 57-80, jan./abr. 2007.

FETT, C.; FETT, W. Filosofia, ciência e a formação do profissional de artes marciais. Motriz, Rio Claro, v. I5, n. I, p. |73- I 84 jan./mar. 2009.

FOUCAULT, M. Segurança, território e população. São Paulo: Martins Fontes, 2008.

FOUCAULT, M. Microfísica do poder. Rio de Janeiro: Graal, 2009. 
FOUCAULT, M. A ordem do discurso: aula inaugural no Còllege de France, pronunciada em 2 de dezembro de 1970. São Paulo: Loyola, 2009.

FOUCAULT, M. A arqueologia do saber. 6. ed. Rio de Janeiro: Forense Universitária, 2010.

GOMES, M. et al. Ensino das lutas: dos princípios condicionais aos grupos situacionais. Movimento, Porto Alegre, v. 16, n. 2, p. 207-227, abr./jun. 2010.

GONÇALVES JUNIOR, L; DRIGO, A. A já regulamentada profissão Educação Física e as artes marciais. Motriz, Rio Claro, v. 7, n. 2, p. I31-132, jul./dez. 2001.

GONZÁLEZ. F. Esportivização. In: GONZÁLEZ, F.; FENSTERSEIFER, P. Dicionário Crítico de Educação Física. ljuí: Ed. da Unijuí, 2005. p. 170- 174.

LAGE, V.; GONÇALVES JUNIOR, L. Karatê-do como própria vida. Motriz, Rio Claro, v. I 3, n. I, p. 33-42, jan./mar. 2007.

LARROSA, J. Lenguaje y educación. Revista Brasileira de Educação, Rio de Janeiro, n. I6, p. 68-80, jan./abr. 2001.

LARROSA, J. O ensaio e a escrita acadêmica. Educação \& Realidade, Porto Alegre, v. 28, n. 2, p. $101-1 \mid$, jan./dez. 2003.

LOPES, L; TAVARES, O. A prática pedagógica dos mestres de caratê da grande vitória (ES). Pensar a Prática, Goiânia, v. I I, n. I, p. 91-97, jan./jul. 2008.

MAINGUENEAU, D. Novas tendências em análise do discurso. 3. ed. Campinas: Pontes, 1997.

NASCIMENTO, P. Organização e trato pedagógico do conteúdo de lutas na Educação Física escolar. Motrivivência, Florianópolis, ano 20, n. 31 , p. 36-49, dez. 2008.

NASCIMENTO, P.; ALMEIDA, L. A tematização das lutas na Educação Física Escolar: restrições e possibilidades. Movimento, Porto Alegre, v. 13, n. 3, p. 9| - I I0, set./dez. 2007.

RIOS, G. O processo de esportivização do taekwondo. Pensar a Prática, Goiânia, v. 8, n. I, p. 37-54, jan./jun. 2005.

RODRIGUES, R. Fazer kendo e pensar a educação do corpo. Motriz, Rio Claro, v. I 5, n. 3, p. 648-656, jul./set. 2009.

SAID, E. Orientalismo: o oriente como invenção do ocidente. São Paulo: Companhia das Letras, 2007.

SILVA, M.; CARVALHO, M. Análise da suplementação nutricional dos atletas da seleção brasiliense de karatê. Revista Brasileira de Ciências do Esporte, Campinas, v. 24, n. I , p. 127 137, set. 2002.

SILVA, T. O currículo como fetiche: a prática e a política do texto curricular. Belo Horizonte: Autêntica, 2003. 
SILVEIRAJÚNIOR. E. R.; CARDOSO, C. L. Qigong: uma contribuição para a Educação Física escolar. Motrivivência, Florianópolis, ano 16, n. 23, p. 83-101, dez. 2004.

TRUSZ, R.; NUNES, A. A evolução dos esportes de combate no currículo do Curso de Educação Física da UFRGS. Movimento, Porto Alegre, v. I3, n. I, p. I 79-204, jan./abr. 2007. VEIGA-NETO, A. Foucault e a educação. 2. ed. Belo Horizonte: Autêntica, 2007.

YONEZAWA, F. Algo se move: um elogio filosófico-ético à prática do combate como arte e educação. Motriz, Rio Claro, v. I6, n. 2, p. 348-358, abr./jun. 2010.

Recebido em: 30 maio 201 I Aprovado em: 18 abr. 2012

Endereço para correspondência: Arisson Vinícius Landgraf Gonçalves

Rua Forte Santana, n. 7/2, Parque Residencial Coelho, Rio Grande/RS CEP:96202-180

\section{APÊNDICE}

QUADRO I - Referência dos artigos que discutem as práticas das Artes Marciais e Lutas selecionadas dos periódicos nacionais: Revista Motrivivência, Revista Motriz, Revista Movimento, Revista Pensar a Prática e Revista Brasileira de Ciências do Esporte (RBCE).

\begin{tabular}{|c|c|c|c|c|c|c|}
\hline & REVISTA & ANO & VOL & $\mathrm{N}$ & TÍTULO & AUTOR (RES) \\
\hline I & Motrivivência & 2004 & 16 & 23 & $\begin{array}{l}\text { QIGONG: UMACONTRIBUIÇÃO } \\
\text { PARA A EDUCAÇÃO FISICA } \\
\text { ESCOLAR }\end{array}$ & $\begin{array}{l}\text { Edson Roneida Silveira } \\
\text { Júnior; Carlos Luiz } \\
\text { Cardoso. }\end{array}$ \\
\hline 2 & Motrivivência & 2008 & 20 & 31 & $\begin{array}{l}\text { ORGANIZAÇÃO E TRATO } \\
\text { PEDAGÓGICO } \\
\text { DO CONTEÚDO DE LUTAS NA } \\
\text { EDUCAÇÃO } \\
\text { FÍSICA ESCOLAR }\end{array}$ & $\begin{array}{l}\text { Paulo Rogério Barbosa } \\
\text { do Nascimento. }\end{array}$ \\
\hline 3 & Motrivivência & 2008 & 20 & 31 & $\begin{array}{l}\text { LUTAS E ARTES MARCIAIS NA } \\
\text { ESCOLA: "DAS BRIGAS AOS } \\
\text { JOGOS COM REGRAS", DE } \\
\text { JEAN-CLAUDE OLIVIER [PORTO } \\
\text { ALEGRE: ARTMED, 2000] }\end{array}$ & Fabiano Filier Cazetto. \\
\hline
\end{tabular}




\begin{tabular}{|c|c|c|c|c|c|c|}
\hline 4 & Motrivivência & 2010 & 22 & 34 & $\begin{array}{l}\text { JIU-JITSU BRASILEIRO E VALE- } \\
\text { TUDO: O USO DE NOVAS } \\
\text { TECNOLOGIAS NO ENSINODE } \\
\text { LUTAS E ARTES MARCIAIS }\end{array}$ & Fabiano Filier Cazetto. \\
\hline & REVISTA & ANO & VOL & $\mathrm{N}$ & TÍTULO & AUTOR (RES) \\
\hline 5 & Motriz & 2001 & 7 & 2 & $\begin{array}{l}\text { A JÁ REGULAMENTADA } \\
\text { PROFISSÃO EDUCAÇÃO FÍSICA } \\
\text { E AS ARTES MARCIAIS }\end{array}$ & $\begin{array}{l}\text { Luiz Gonçalves } \\
\text { Junior; Alexandre } \\
\text { Janota Drigo. }\end{array}$ \\
\hline 6 & Motriz & 2007 & 13 & I & $\begin{array}{l}\text { KARATÊ-DO COMO PRÓPRIA } \\
\text { VIDA }\end{array}$ & $\begin{array}{l}\text { Victor Lage; Luiz } \\
\text { Gonçalves Junior. }\end{array}$ \\
\hline 7 & Motriz & 2009 & 15 & I & $\begin{array}{l}\text { FILOSOFIA, CIÊNCIA E A FOR- } \\
\text { MAÇÃO DO PROFISSIONAL DE } \\
\text { ARTES MARCIAIS }\end{array}$ & $\begin{array}{l}\text { Carlos Alexandre Fett; } \\
\text { Waléria Christiane } \\
\text { Rezende Fett. }\end{array}$ \\
\hline 8 & Motriz & 2009 & 15 & 2 & $\begin{array}{l}\text { LUTAS E ESCOLAS DE OFÍCIO: } \\
\text { ANALISANDO O JUDÔ } \\
\text { BRASILEIRO }\end{array}$ & $\begin{array}{l}\text { Alexandre Janotta } \\
\text { Drigo. }\end{array}$ \\
\hline 9 & Motriz & 2009 & & & $\begin{array}{l}\text { FAZER KENDO E PENSAR A } \\
\text { EDUCAÇÃO DO CORPO }\end{array}$ & Rogério Rodrigues. \\
\hline 10 & Motriz & 2010 & 16 & 1 & $\begin{array}{l}\text { PRODUÇÃO ACADÊMICA EM } \\
\text { LUTAS, ARTES MARCIAIS E } \\
\text { ESPORTES DE COMBATE }\end{array}$ & $\begin{array}{l}\text { Walter Roberto } \\
\text { Correia; Emerson } \\
\text { Franchini. }\end{array}$ \\
\hline 11 & Motriz & 2010 & 16 & 2 & $\begin{array}{l}\text { ALGO SE MOVE: UM ELOGIO } \\
\text { FILOSÓFICO-ÉTICO ÀPRÁTICA } \\
\text { DO COMBATE COMO ARTE E } \\
\text { EDUCAÇÃO }\end{array}$ & $\begin{array}{l}\text { Fernando Hiromi } \\
\text { Yonezawa. }\end{array}$ \\
\hline 12 & Motriz & 2010 & 16 & 3 & $\begin{array}{l}\text { BUJUTSU, BUDÔ, ESPORTE } \\
\text { DE LUTA }\end{array}$ & $\begin{array}{l}\text { Carlos José Martins; } \\
\text { Cláudia Kanashiro. }\end{array}$ \\
\hline 13 & Motriz & 2010 & 16 & 3 & $\begin{array}{l}\text { A INGESTÃO DE CAFEÍNA NÃO } \\
\text { MELHORA O DESEMPENHO DE } \\
\text { ATLETAS DE JUDÔ }\end{array}$ & $\begin{array}{l}\text { Lucas Adriano Pereira; } \\
\text { Edílson Serpeloni } \\
\text { Cyrino;AdemarAvelar; } \\
\text { Alexandre Queiroz } \\
\text { Segantin; Juliana Melo } \\
\text { Altimari; } \\
\text { Michele Caroline de } \\
\text { Costa Trindade; } \\
\text { Leandro Ricardo } \\
\text { Altimari. }\end{array}$ \\
\hline 14 & Movimento & 2004 & 10 & 3 & $\begin{array}{l}\text { VISANDO A MODERNIDADE } \\
\text { ARCO E FLECHA E A } \\
\text { MODERNIZAÇÃO DO JAPÃO }\end{array}$ & Allen Guttman. \\
\hline 15 & Movimento & 2007 & 13 & I & $\begin{array}{l}\text { A EVOLUÇÃO DOS ESPORTES } \\
\text { DE COMBATE NO CURRÍCULO } \\
\text { DO CURSO DE EDUCAÇÃO } \\
\text { FÍSICA DA UFRGS }\end{array}$ & $\begin{array}{l}\text { Rodrigo Augusto } \\
\text { Trusz; Alexandre Velly } \\
\text { Nunes. }\end{array}$ \\
\hline
\end{tabular}




\begin{tabular}{|c|c|c|c|c|c|c|}
\hline 16 & Movimento & 2007 & 13 & 3 & $\begin{array}{l}\text { A TEMATIZAÇÃO DAS LUTAS } \\
\text { NA EDUCAÇÃO FÍSICA } \\
\text { ESCOLAR: RESTRIÇÕES E } \\
\text { POSSIBILIDADES } \\
\end{array}$ & $\begin{array}{l}\text { Paulo Rogério Barbosa } \\
\text { do Nascimento; } \\
\text { Luciano de Almeida. }\end{array}$ \\
\hline & REVISTA & ANO & VOL & $\mathrm{N}$ & TÍTULO & AUTOR (RES) \\
\hline 17 & Movimento & 2009 & 15 & I & $\begin{array}{l}\text { A CONSTITUIÇÃO DE UM SUB- } \\
\text { CAMPO DO ESPORTE: O CASO } \\
\text { DO TAEKWONDO }\end{array}$ & $\begin{array}{l}\text { Thiago Pimenta; } \\
\text { Wanderley Marchi } \\
\text { Júnior. }\end{array}$ \\
\hline 18 & Movimento & 2010 & 16 & 2 & $\begin{array}{l}\text { ENSINO DAS LUTAS: DOS PRIN- } \\
\text { CÍPIOS CONDICIONAIS AOS } \\
\text { GRUPOS SITUACIONAIS }\end{array}$ & $\begin{array}{l}\text { Mariana Simões } \\
\text { Pimentel Gomes; } \\
\text { Marcio Pereira } \\
\text { Morato; Edison Du- } \\
\text { arte; José Júlio Gavião } \\
\text { de Almeida. }\end{array}$ \\
\hline 19 & $\begin{array}{l}\text { Pensar a } \\
\text { Prática }\end{array}$ & $\begin{array}{l}1999- \\
2000\end{array}$ & 3 & 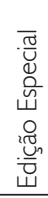 & $\begin{array}{l}\text { EM BUSCA DA CONSTRUÇÃO } \\
\text { DE UMA PROPOSTA TEÓRICO- } \\
\text { METODOLÓGICA } \\
\text { PARA O ENSINO DO JUDÔ } \\
\text { ESCOLAR }\end{array}$ & $\begin{array}{l}\text { Orozimbo Cordeiro } \\
\text { Júnior. }\end{array}$ \\
\hline 20 & \begin{tabular}{|l|} 
Pensar a \\
Prática
\end{tabular} & 2005 & 8 & 1 & $\begin{array}{l}\text { O PROCESSO DE ESPORTIVIZA- } \\
\text { ÇÃO DO TAEKWONDO }\end{array}$ & Gleyson Batista Rios \\
\hline 21 & $\begin{array}{l}\text { Pensar a } \\
\text { Prática }\end{array}$ & 2008 & 11 & I & $\begin{array}{l}\text { A PRÁTICA PEDAGÓGICA DOS } \\
\text { MESTRES DE CARATÊ DA GRAN- } \\
\text { DE VITÓRIA (ES) }\end{array}$ & $\begin{array}{l}\text { Yúri Márcio Lopes; } \\
\text { Otávio Guimarães } \\
\text { Tavares }\end{array}$ \\
\hline 22 & $\begin{array}{l}\text { Pensar a } \\
\text { Prática }\end{array}$ & 2008 & 11 & 3 & $\begin{array}{l}\text { CONTROLE DE SI, DOR E } \\
\text { REPRESENTAÇÃO FEMININA } \\
\text { ENTRE } \\
\text { LUTADORES(AS) DE MIXED } \\
\text { MARTIAL ARTS } \\
\end{array}$ & $\begin{array}{l}\text { Samuel Oliveira } \\
\text { Thomazini; Cláudia } \\
\text { Emília Aguiar Moraes; } \\
\text { Felipe Quintão } \\
\text { Almeida }\end{array}$ \\
\hline 23 & $\begin{array}{l}\text { Pensar a } \\
\text { Prática }\end{array}$ & 2010 & 13 & 3 & $\begin{array}{l}\text { A IDENTIFICAÇÃO DOS ESTI- } \\
\text { LOS DE ENSINO DOS PRO- } \\
\text { FESSORES DAS ARTES MAR- } \\
\text { CIAIS CHINESAS (WUSHU) NO } \\
\text { BRASIL }\end{array}$ & $\begin{array}{l}\text { Marcelo Moreira } \\
\text { Antunes; Diego Luz } \\
\text { Moura }\end{array}$ \\
\hline 24 & RBCE & 2002 & 24 & I & $\begin{array}{l}\text { ANÁLISE DA SUPLEMENTAÇÃO } \\
\text { NUTRICIONAL DOS ATLETAS } \\
\text { DA SELEÇÃO BRASILIENSE DE } \\
\text { KARATÊ }\end{array}$ & $\begin{array}{l}\text { Michel Santos da } \\
\text { Silva; Michel Soares de } \\
\text { Carvalho. }\end{array}$ \\
\hline 25 & RBCE & 2002 & 24 & I & $\begin{array}{l}\text { AVALIAÇÃO DA INTENSIDADE } \\
\text { DE ESFORÇO DA LUTA DE } \\
\text { CARATÊ POR MEIO } \\
\text { DA MONITORIZAÇÃO DA } \\
\text { FREQÜÊNCIA CARDÍACA }\end{array}$ & $\begin{array}{l}\text { Dr. Marcelo de Castro } \\
\text { César; Dr. Ídico Luiz } \\
\text { Pellegrinotti; Eduardo } \\
\text { Silvestre Penatti; } \\
\text { Graziela Augusta } \\
\text { Chiavoloni. }\end{array}$ \\
\hline
\end{tabular}

